\title{
PRE-DOMESTICATION BOTTLENECKS OF THE CULTIVATED SEAWEED GRACILARIA CHILENSIS
}

\author{
Oscar Huanel ${ }^{1}$, Suany Quesada-Calderón ${ }^{2}$, Sarai Morales-González ${ }^{2}$, Pablo \\ Saenz-Agudelo ${ }^{2}$, Stephane Mauger ${ }^{3}$, Wendy Nelson ${ }^{4}$, Natalia Arakaki ${ }^{5}$, Cristia Ríos ${ }^{2}$, \\ Sylvain Faugeron ${ }^{6}$, and Marie-Laure Guillemin ${ }^{7}$ \\ ${ }^{1}$ Pontifical Catholic University of Chile \\ ${ }^{2}$ Instituto de Ciencias Ambientales y Evolutivas, Facultad de Ciencias, Universidad Austral \\ de Chile, Casilla 567 \\ ${ }^{3}$ IRL 3614 Evolutionary Biology and Ecology of Algae, CNRS, Sorbonne Université, \\ Pontificia Universidad Católica de Chile, Universidad Austral de Chile, Station Biologique \\ ${ }^{4}$ National Institute of Water and Atmospheric Research (NIWA),Private Bag \\ 14-901,Wellington 6241, New Zealand \\ ${ }^{5}$ Instituto del Mar del Perú, Banco de Germoplasma de Organismos Acuáticos, Esquina \\ Gamarra y General Valle s/n, Chucuito \\ ${ }^{6}$ Millenium Nucleus Marine Agronomy of Seaweed Holobionts, Facultad de Ciencias \\ Biológicas, Pontificia Universidad Católica de Chile, Casilla 114-D \\ ${ }^{7}$ Millenium Nucleus Marine Agronomy of Seaweed Holobionts, Instituto de Ciencias \\ Ambientales y Evolutivas, Facultad de Ciencias, Universidad Austral de Chile, Casilla 567
}

March 2, 2022

\begin{abstract}
Gracilaria chilensis is the main cultivated seaweed in Chile. The low genetic diversity observed in the Chilean population has been associated with the over-exploitation of natural beds and/or the founder effect that occurred during the post-glacial colonization from New Zealand. How these processes have affected its evolutionary trajectory before farming and incipient domestication is poorly understood. In this study, we used 2,232 SNPs to assess how the species evolutionary history in New Zealand (its region of origin), the founder effect linked to transoceanic dispersion and colonization of South America, and the recent over-exploitation of natural populations have influenced the genetic architecture of G. chilensis in Chile. The contrasting patterns of genetic diversity and structure observed between the two main islands in New Zealand attest to the important effects of Quaternary glacial cycles on G. chilensis. ABC analyses indicated that Chatham Island and South America were colonized independently near the end of the Last Glacial Maximum and emphasized the importance of coastal and oceanic currents during that period. Furthermore, ABC analyses inferred the existence of a recent and strong genetic bottleneck in Chile, matching the period of over-exploitation of the natural beds during the 1970s, followed by rapid demographic expansion linked to active clonal propagation used in farming. Recurrent genetic bottlenecks strongly eroded the genetic diversity of G. chilensis prior to its cultivation, raising important challenges for the management of genetic resources in this incipiently domesticated species.
\end{abstract}

\section{Hosted file}

Population genomics of Gracilaria chilensis consolidated.docx available at https://authorea. com/users/463081/articles/558289-pre-domestication-bottlenecks-of-the-cultivatedseaweed-gracilaria-chilensis 


\section{Hosted file}

Figures . pdf available at https://authorea.com/users/463081/articles/558289-pre-domesticationbottlenecks-of-the-cultivated-seaweed-gracilaria-chilensis

\section{Hosted file}

Tables.pdf available at https://authorea.com/users/463081/articles/558289-pre-domesticationbottlenecks-of-the-cultivated-seaweed-gracilaria-chilensis 